\title{
Lives presidenciais: reflexões iniciais sobre o discurso político digital
}

\author{
Renata de Oliveira CARREON (®) \\ Universidade Estadual de Ponta Grossa (UEPG) \\ Roberto Leiser BARONAS (1) \\ Universidade Federal de São Carlos (UFSCar)
}

\section{○ \\ OPEN ACCESS \\ EDITADO POR \\ - Evandra Grigoletto (UFPE) \\ - Bethania Mariani (UFF) \\ - Gian Luigi de Rosa (UNIROMA) \\ AVALIADO POR \\ - Cristiane Dias (UNICAMP) \\ - Décio Rocha (UERJ) \\ SOBRE OS AUTORES \\ - Renata de Oliveira Carreon \\ Escrita - rascunho original. \\ - Roberto Leiser Baronas \\ Escrita - análise e edição. \\ DATAS \\ - Recebido: 25/10/2020 \\ - Aceito: 28/11/2020 \\ - Publicado: 17/12/2020 \\ COMO CITAR \\ Carreon, R. O.; Baronas, R. L. (2020). Lives presidenciais: reflexões iniciais sobre o discurso político digital. Revista da Abralin, v. 19, n. 3, p. 541-561, 2020.}

\section{RESUMO}

O desenvolvimento de novas tecnologias da comunicação faz com que, cada vez mais, surjam novas práticas discursivas - bem como o inverso também se faz verdadeiro -, sobretudo em relação àquelas ligadas ao uso das redes sociais, que parecem promover um estreitamento da relação entre cidadãos e instâncias do poder democrático. A partir disso, como analistas do discurso, somos instados a nos questionar sobre as categorias que utilizamos para observar, principalmente, o discurso digital. Neste artigo, buscaremos compreender como a utilização de lives por parte do Presidente da República, Jair Bolsonaro, orquestram um rearranjo de práticas político-discursivas que podem se materializar em novos objetos de análise para a Análise do discurso no/do Brasil. Mais especificamente, buscaremos compreender em que medida adotar as lives como forma de "fonte de informação para o povo" faz com que haja um novo modo de se fazer política e de se criar um efeito de proximidade por meio de um discurso verdadeiro, em que a cena de enunciação instaurada opera, na ordem do discurso, com sentidos que delineiam a aproximação dos sujeitos, mas também o próprio regime de verdade. Para tal empreendimento, mobilizaremos o arcabouço teórico-metodológico da Análise do discurso pensada por Dominique Maingueneau e Marie-Anne Paveau.

\section{RESUMEN}

El desarrollo de las nuevas tecnologías de la comunicación hace que surjan nuevas prácticas, especialmente aquellas relacionadas con el uso de las 


\section{REVISTA DA ABRALIN}

redes sociales, que parecen promover una relación más cercana entre la ciudadanía y las instancias de poder democrático. A partir de esto, como analistas del discurso, se nos insta a preguntarnos sobre las categorías que usamos para observar, principalmente, el discurso digital. En este artículo buscaremos comprender cómo el uso de lives por parte del presidente de la República, Jair Bolsonaro, orquesta un reordenamiento de prácticas político-discursivas que pueden materializarse en nuevas formas de producir teoría en el Análisis del Discurso en / desde Brasil, especialmente en lo que se refiere a la noción de escena de enunciación y discurso digital. Más concretamente, buscaremos comprender en qué medida la adopción de transmisiones en directo como forma de "fuente de información para las personas" conducirá a una nueva forma de hacer política y creará un efecto de proximidad a través de un discurso verdadero, en que la escena de la enunciación establecida opera, en el orden del discurso, con significados que perfilan el enfoque de los sujetos, pero también el régimen de la verdad. Para este empeño, movilizaremos el marco teórico-metodológico del Análisis del Discurso diseñado por Dominique Maingueneau y MarieAnne Paveau.

\section{PALAVRAS-CHAVE}

Análise do discurso. Discurso político. Discurso digital. Live. Verdade.

\section{PALABRAS CLAVE}

Análisis del discurso. Discurso político. Discurso digital. Live. Verdad.

\section{Introdução}

Marie-Anne Paveau em L'Analyse du discours numérique. Diccionnaire des formes et des pratiques (2017) [A Análise do discurso digital: dicionário das formas e das práticas] propõe "novos conceitos, ferramentas e limites para compreender o funcionamento dos discursos nativos da internet a partir de uma perspectiva qualitativa e ecológica" (PAVEAU, 2017, p. 8, tradução nossa), isto é, para a autora, é necessário repensar o chamado contexto "extralinguístico" como um ecossistema em que o discurso é elaborado e não como pano de fundo do discurso (PAVEAU, 2013, p. 3, tradução nossa). Embora possamos afirmar que o "extralinguístico" para a AD nunca foi pano de fundo, uma vez que a exterioridade constitutiva está ligada às condições de produção dos discursos, entendemos que a autora perscruta dar protagonismo, também, ao uso da máquina, entendido por ela como 


\section{REVISTA DA ABRALIN}

"extralinguístico". Em outras palavras, para Paveau, é preciso deslocar-se da visão dualista entre sujeito e língua para reconhecer o papel de agentes não humanos nas produções linguísticas e, por isso, levar em consideração, também, o instrumental e as funcionalidades disponibilizadas pela máquina. Nesse sentido, para a pesquisadora francesa

(...) os discursos digitais nativos não são de ordem puramente linguageira, as determinações técnicas coconstroem as formas tecnolinguageiras e as perspectivas logo-e antropocentradas devem ser descartadas em favor de uma perspectiva ecológica integrativa que reconhece o papel dos agentes não humanos nas produções linguageiras. (PAVEAU, 2017, p. 11, tradução nossa)

Dessa forma, preocupada com o modo de organização dos discursos em função do advento da Web 2.0, Paveau reflete sobre a singularidade dos discursos digitais, inerentemente sincréticos, uma vez que mesclam textos, imagens, sons. Autores brasileiros, como Cristiane dias, têm se debruçado há algumas décadas em mapear tal singularidade dos discursos digitais, o que envolve repensar desde as questões de circulação e a ilusão de centralidade do sujeito, até a própria questão de como o discurso digital significa. Nesse sentido, a autora afirma:

\footnotetext{
É preciso buscar a falha e compreender como esses aplicativos ou sistemas lógico-digitais significam pelo funcionamento do imaginário da tecnologia como a promessa de uma superação de "fragilidades" da vida. Sair desse lugar de transparência significa abrir espaço para a produção de outros sentidos para a tecnologia, deslocando os objetivos para os quais foram forjadas. Colocando sua eficácia em questão e subvertendo seu uso em prol das necessidades da vida em sociedade. (DIAS, 2018, p. 64)
}

Considerando esse novo olhar sobre o modo de se pensar o discurso, é preciso ainda afirmar que a forma de se fazer política se metamorfoseou, uma vez que as redes criam o efeito de proximidade entre político e cidadão, em que a relação entre ambos aparenta não ter intermediários e o último passa a ter acesso ao que parece ser a vida pessoal do primeiro. No campo do político, as redes perpetuam uma necessidade do processo democrático no qual o cidadão anseia se fazer ouvido, corroborando o efeito de proximidade que, segundo o historiador Rosanvallon, remete a uma radical particularização da relação entre cidadãos e o poder: "Eles [cidadãos] estão esperando que o poder esteja atento às suas dificuldades, que se mostrem verdadeiramente preocupados com o modo como vivem as pessoas comuns" (ROSANVALLON, 2008, p. 267, tradução nossa). Para além do fenômeno de conectividade das redes, as lives, vídeos realizados ao vivo, parecem promover e impor nova mutação ao discurso político. Defendemos, aqui, que as lives presidenciais brasileiras, protagonizadas por Jair Bolsonaro, têm se apresentado como um novo modo de se fazer política e de se governar, não mais o pronunciamento oficial como alhures, mas uma espécie de bate-papo político, pois além do efeito de proximidade com o eleitor, as lives parecem impelir ao analista um novo olhar sobre a própria configuração da cena de enunciação que, nativa do digital, pulveriza as restrições da cena genérica em função das cenografias digitais ali engendradas. 


\section{REVISTA DA ABRALIN}

\section{Redes e política}

As novas tecnologias da comunicação imprimem não só novas práticas verbais, mas modificam a própria noção de discursividade e, particularmente, de gêneros do discurso. (MAINGUENEAU, 2015a). Para o autor,

\footnotetext{
As novas tecnologias da comunicação não são apenas instrumentos a serviço de uma comunicação verbal que permaneceria fundamentalmente inalterada elas modificam a materialidade do que se entende por "discurso", com tudo o que isso implica em termos de relações sociais e de construção da subjetividade. (MAINGUENEAU, 2015a, p. 170)
}

Assim, tendo como horizonte as profundas modificações impostas ao discurso e, por consequência, às relações sociais é que passamos a observar um fenômeno específico: as redes sociais. Podemos afirmar que as redes aumentaram o efeito de proximidade entre político e eleitor: embora não ocupem fisicamente o mesmo espaço, virtualmente a relação é estreitada, já que agora o eleitor passa a ter acesso ao que aparenta ser a vida pessoal do político: seus posts, compartilhamentos e, além disso, ainda pode escolher comentar e ser lido. Se, por um lado a televisão causava um efeito de realidade (CARREON, 2018), porque o que era da ordem do mostrado parecia de fato ser real, há, com as redes sociais, o efeito de proximidade. O exaustivo compartilhamento de usuários na rede aproxima e torna tudo "à distância de um clique". Tal proximidade, certamente, não põe os sujeitos na mesma relação de poder, mas cria efeitos de sentido em torno dessa relação, corroborando os imaginários do eleitorado acerca do que deve ou não ser e fazer o bom político.

Se, na fala de palanque, a massa se aglomerava e constituía uma unidade, a partir do rádio o processo passa a ser individualizado, fazendo com que as pessoas deixem de se reunir junto ao político e passem a ter acesso a ele de maneira individual em seu domicílio. Nesse sentido, por um lado, as redes levam à potência máxima o movimento que começou com o rádio, em que as pessoas têm acesso ao corpo político de maneira individualizada no celular ou computador, simbolicamente acessível a um clique. Não é necessário aglomerar-se para o que quer que seja e, além disso, não é necessário nem mesmo ser você: as redes permitem a escolha de pseudônimos, avatares, fazendo com que o usuário possa escolher quem ele quer ser. Por outro lado, as especificidades das redes fazem com que os indivíduos, de suas casas, possam estar conectados, promovendo, literalmente, uma rede social e construindo coletividades facilitadas pelos aparatos técnicos, sejam elas por meio de grupos no Facebook ou a adesão a uma hashtag (\#). Sobre a ambivalência da comunicação na internet, que se dá tanto individual quanto no coletivo, Castells afirma:

\footnotetext{
É comunicação de massa porque processa mensagens de muitos para muitos, com o potencial de alcançar uma multiplicidade de receptores e de se conectar a um número infindável de redes que transmitem informações digitalizadas pela vizinhança ou pelo mundo. É autocomunicação porque a produção da mensagem é decidida de modo autônomo pelo remetente, a designação do receptor é autodirecionada e a recuperação de mensagens das redes de comunicação é autosselecionada. (CASTELLS, 2013, p. 15)
} 


\section{REVISTA DA ABRALIN}

Assim, enquanto as redes corroboram a individualização da massa, mas, ao mesmo tempo, permitem que ela se conecte virtualmente, o efeito de proximidade de político-eleitor torna-se ainda maior, especialmente por, aparentemente, não haver mais intermediários entre ambos; não há jornalistas, entrevistadores ou toda uma rede de comunicações. As redes sociais produzem um efeito de fazer sentir que não há intermediação e o acesso é livre, mesmo quando se sabe, talvez, que, em se tratando de atores políticos, geralmente, seus perfis em redes sociais são gerenciados por toda uma gama de profissionais de diversas áreas, o que Maingueneau denominou "locutores problemáticos" para designar aquele que não é o locutor da "representação habitual da fala", "único e identificável, ao mesmo tempo, agente da enunciação e responsável por ela" (2015a, p. 175). Dessa forma, acreditamos que as redes operem no âmbito de duplo esquecimento: (i) esquece-se, pelo efeito de proximidade, que pode haver intermediários no processo comunicativo; (ii) esquece-se que a proximidade é apenas efeito.

Ao descrever as figuras de legitimidade democráticas, Rosanvallon (2008) afirma que a "legitimidade de proximidade" consiste no estreitamento da relação entre cidadãos e instâncias do poder democrático, já que cada vez mais os cidadãos querem ser ouvidos e levados em conta. Para o historiador, tal necessidade de inclusão faz com que haja uma demanda por atenção à particularidade, forçando a generalidade comum da instância política a se aprofundar na vida, na prática, no real do cidadão. Assim, o cidadão passa a exigir uma política de presença, que cobra não só a honestidade de seu candidato, mas também sua presença, sua proximidade, sua empatia e em última instância o estar junto. A partir disso, podemos afirmar que as redes sociais refletem uma necessidade do sistema político democrático em que o cidadão quer falar, se fazer ouvido e compreendido em suas premências, e o efeito de proximidade das redes, mesmo configurando um esquecimento do sujeito, faz com que as discursividades sejam legitimadas em ambas as instâncias.

Surge um novo modo de se governar: não mais o corpo a corpo, o tête-à-tête, mas o efeito de proximidade das redes, sem intermediários, criando laços discursivos, por meio da cena instaurada e seu ethos associado, com o sujeito que ali enuncia. Assim, emerge uma nova configuração política e, com ela, um novo tipo de governante.

\section{Conceituação discursiva de "live"}

Para Cristiane Dias, diferentemente de outros objetos, no nosso entendimento, o discurso digital é pensado em função de sua circulação, antes mesmo de se analisar a constituição ou formulação:

É nessa perspectiva que tenho trabalhado incessantemente sobre o momento da circulação ao refletir sobre o digital, pois entendo que é pela circulação (compartilhamento, viralização, comentários, postagens, hashtags, memes, links...) que o digital se formula e se constitui. De outro modo, diríamos que o digital se formula ao circular. E isso faz diferença na produção dos sentidos. Essa mudança na ordem não quer estabelecer uma relação de anterioridade de um momento em relação ao outro, mas de 


\section{REVISTA DA ABRALIN}

perspectiva. Olhar o processo de produção dos discursos pela via da circulação tem a ver com um sentido que se produz no efêmero, no agora" (DIAS, 2018, p. 29)

Tendo esses pressupostos em vista, propusemo-nos a pensar as lives presidenciais por seu caráter aparentemente único e inédito em certo sentido. Apesar de não ser de fato novo um presidente se utilizar de suas redes sociais para criar um efeito de proximidade com seu eleitorado, o fato de fazê-lo por vídeo e ao vivo, numa espécie de bate papo político, faz com que essa cena genérica - tal qual pensada por Maingueneau (2015a) como associada ao gênero, realidade tangível, imediata, para os usuários do discurso - seja ressignificada em função de seus vínculos institucionais.

Conforme enunciado, entendemos que, em se tratando de redes sociais e discurso político, as redes operam um duplo esquecimento: (i) esquece-se, pelo efeito de proximidade, que pode haver intermediários no processo comunicativo; (ii) esquece-se que a proximidade é apenas efeito. Sobre essa questão, é possível afirmar que o atual modo de governar do Presidente da República, Jair Bolsonaro, está bastante associado ao seu uso peculiar das redes, já que ele declaradamente é o usuário delas, ou seja, é sabido por parte da população que é ele mesmo quem posta, compartilha, comenta, não sua assessoria. Se der mos uma espiada no retrovisor da história, veremos que Bolsonaro assim procede desde a sua campanha para presidente. Já aí temos um primeiro ponto de ruptura com o modo de se fazer política até então: o que antes era um efeito de proximidade criado a partir de um esquecimento do interlocutor em relação aos intermediários do discurso digital passa agora a, de fato, ser próximo, quase íntimo, uma vez que o sujeito se dispõe a estar ali, ele mesmo, junto de seus eleitores. Assim, o efeito de proximidade, já criado pelas redes, passa também a ser o de intimidade. Há cumplicidade quando o eleitorado vê o ator político se dispondo, ele mesmo, a responder. Em outras palavras, aquilo que "excede qualquer distinção simples entre público e privado: a 'extimidade' subverte as fronteiras entre o público e o privado" (MAINGUENEAU, 2015a, p. 175). Para Paveau (2017) "a extimidade na internet e, principalmente, nas redes sociais digitais da web participativa, consiste na externalização da privacidade dos usuários da internet para fins de validação da imagem de si." (PAVEAU, 2017, p. 185, tradução nossa). Desse modo, a extimidade engendrada pelas redes faz com que esse sujeito político valide suas imagens de si, diante daqueles que aderem ao seu mundo éthico, por meio desse efeito de proximidade.

Entretanto, quando se vai além do simples comentário ou compartilhamento, mas se produzem lives - vídeos realizados ao vivo nas redes de forma pública ou para o seu conjunto de seguidores a intimidade parece aumentar. Ainda segundo Paveau:

\footnotetext{
Os dispositivos de webcam dizem respeito ao mesmo tipo de exteriorização de si: o sujeito que se filma se inscreve na relação com o outro possibilitada pela internet, em uma multiplicidade de trocas, dentre as quais trocas verbais; portanto, a web-íntima é suscetível de participar da tecnodiscursividade. (PAVEAU, 2017, p. 194, tradução nossa)
}

Desse modo, a exteriorização de si e o efeito de proximidade por meio da intimidade parecem confluir para criar uma relação única com o eleitorado. Assim, como o advento da televisão criou esse efeito de realidade ao trazer para a cena o corpo e, sobretudo, o rosto do sujeito, a live une os dois universos: tanto esse corpo que se propõe dar a ver, quanto as características específicas de 


\section{REVISTA DA ABRALIN}

compartilhamento das redes, que fazem com que, como dissemos, a circulação seja pensada em sua primazia em relação à própria formulação de discursos. Implica dizer, portanto, que a circulação de um vídeo ao vivo nas redes empreende um movimento específico, distinto do da televisão. Na televisão, ainda que o programa seja realizado ao vivo, sempre haverá um mediador: o apresentador do programa, o repórter que entrevista, um mediador de debates; além disso, a interação com o público que assiste é bastante restrita. A live, geralmente realizada em redes sociais, não tem mediadores: o sujeito liga a sua câmera, podendo inclusive ser do próprio celular, não necessitando de aparatos técnicos mais específicos, e fala ao seu público; também a rede permite que aqueles que acompanham possam interagir em tempo real com a gravação, enviando comentários, perguntas ou reações; ainda, é preciso lembrar, que a live pode ser disponibilizada em outras plataformas depois, como o Youtube, onde o vídeo poderá ser assistido por mais pessoas, além de curtido e comentado, produzindo uma das características mais marcantes do discurso digital que é a sua ampliação. Além disso, a live, por meio de dispositivos técnicos, administra quem pode e quem não pode assistir, instituindo uma ordem do discurso totalmente nova, isto é, não são mais os locutores que podem ou não podem dizer, como outrora, mas agora também os destinatários passam por esse crivo de rarefação.

A partir da hipótese de que as lives empreendem um movimento específico em relação ao discurso político digital, é preciso compreendê-las à luz da cena de enunciação, conforme postulada por Maingueneau em diversos trabalhos. O autor toma de empréstimo do teatro o conceito de cena para pensá-lo a partir do arcabouço da Análise do discurso. Por isso, para ele, toda enunciação está ligada a certa teatralidade que lhe é mais ou menos imposta em razão do "ritual" que se estabelece em uma espécie de contrato entre os falantes. Assim, o autor divide a cena da enunciação em três: cena englobante, cena genérica e cenografia. A cena englobante corresponde ao tipo de discurso, uma rede de práticas discursivas que cortam um setor da atividade social: publicitário, religioso, político, filosófico. Sendo a cena englobante o quadro a partir do qual os enunciados podem ser produzidos e interpretados, a cena genérica é associada ao gênero, realidade tangível, imediata, para os usuários do discurso. Ainda, "enunciar não é somente ativar as normas de uma instituição de fala prévia, como ocorre em uma cena englobante e em uma cena genérica, é construir sobre essa base uma encenação singular da enunciação: uma cenografia." (MAINGUENEAU, 2015b, p. 70, tradução nossa). Em outras palavras, os sujeitos desempenharão, na teatralidade que a cena de enunciação impõe ao sujeito, um papel frequentemente previsto pela cena genérica, e esse papel, entendido aqui como cenografia, estará diretamente ligado à construção do ethos. Nas palavras de Maingueneau:

\footnotetext{
Normalmente, a cenografia deve ser legitimada ou relegitimada pela própria enunciação que sobre ela se apoia: o universo construído pelo enunciado deve especificar e validar a cenografia através da qual ele surge. (MAINGUENEAU, 2020, p. 19)
}

Tais conceitos podem ser atribuídos ao que o autor chama de "sistema clássico" de gêneros do discurso que são estruturados pela hierarquia dos planos da cena de enunciação: Cena englobante > Cena genérica > Cenografia, sendo a cena genérica o centro desse sistema. Já em se tratando de Web, a cena genérica e a cena englobante são enfraquecidas (MAINGUENEAU, 2015a, p. 162) para dar lugar à cenografia, cujo papel-chave mobiliza recursos multimodais e operações hipertextuais. 


\section{REVISTA DA ABRALIN}

Assim, passa a figurar na teoria do autor a noção de "cenografia digital" para pensar na encenação da enunciação nessa genericidade implicada pela Web:

Ao disponibilizar uma carta em um site da internet, ela será integrada a uma nova configuração, uma
cenografia digital, que reveste a cenografia propriamente verbal: ela será ao mesmo tempo uma ima-
gem e uma tela, um suporte de operações (por exemplo, pode-se clicar sobre determinada palavra ou
grupo de palavras), um constituinte da arquitetura do site no qual ela figura. (MAINGUENEAU, 2015a,
p. 162)

Portanto, as transformações em curso operadas pelo advento da Web fazem com que o analista seja impelido a (re)ler questões ligadas aos gêneros discursivos e a cena nele implicada para pensar em uma disposição de elementos que traga não mais o gênero, mas especialmente, a cenografia como centro do digital. O autor ainda afirma que é preciso tratar, também, da questão das novas textualidades da Web, uma vez que ela tende a desestabilizar a hierarquia entre o que seria o texto principal e os paratextos.

A Web pode integrar gêneros nativos (hashtags, blogs, sites de informação), que poderíamos opor ao que o autor chama de "clássicos". Tais gêneros são "formatações pouco restritivas, que possibilitam muitas cenografias" (MAINGUENEAU, 2015a, p. 165), o que reitera a tese de que, na Web, cenas genérica e englobante são coadjuvantes na construção da teatralidade que envolve a enunciação, isto é, a englobante e a cena genérica são os ambientes necessários para que a cenografia se manifeste. Desse modo, a "textualidade navegante" da Web, em oposição à textualidade "planejada" de gêneros clássicos, faz com que haja uma "des-diferenciação" dos múltiplos domínios da fala e, assim, a própria noção de "remetente" e "destinatário" implicados na comunicação é questionada, uma vez que a concepção de "turnos de fala" passa por uma fragmentação ou ruptura quando se pensa que o destinatário não só não está presente espacialmente, mas também temporalmente e, ainda, muitas vezes, não é possível delimitar um destinatário preciso, já que algo publicado na Web circula de diferentes maneiras e de forma bastante imprevisível.

Pensemos na configuração particular da live. Como dissemos anteriormente, é um vídeo exibido ao vivo e que aparentemente elimina intermediários: o locutor fala diretamente a seu público. A configuração das novas tecnologias da Web faz com que não só usuários on-line possam assistir, como também, ao terminar, o vídeo ficará disponível em algum tipo de canal para ser acessado em qualquer outro momento, rompendo com a temporalidade e espacialidade típicos do processo de comunicação. Além disso, tal vídeo poderá ser localizado posteriormente em sites de busca ou no próprio site em que estará alojado. Essas primeiras considerações são importantes para que se disponha a live como um "cibergênero", isto é, um gênero nascido no digital e, ao mesmo tempo, a distinga de outros gêneros ao vivo, como programas de televisão que, sincronamente, pressupõem a presença temporal do telespectador.

Tomaremos aqui as lives como cena genérica tal qual pensada por Maingueneau. Entretanto, é preciso observar também as particularidades da cena de enunciação que ampara a teatralidade da comunicação na/da Web. A cada gênero são associadas: 


\section{REVISTA DA ABRALIN}

- Uma ou mais finalidades: é possível haver uma ou mais finalidades de um gênero, o que, em boa medida, regula as estratégias dos sujeitos tanto em relação à produção quanto à interpretação dos enunciados. As lives, tendo um formato e, consequentemente, uma cenografia, bastante diversificado a depender daquele que a mobiliza, pode ter diversas finalidades comunicativas que sempre pressupõem, em um primeiro momento, a sincronicidade entre locutores. Assim, as finalidades podem variar desde ministrar uma palestra, fazer a defesa de um doutorado, arrecadar fundos por meio de um show ao vivo, adquirir mais clientes etc.

- Papéis para os parceiros: Há papéis desempenhados em um gênero do discurso que atribuem direitos e deveres aos participantes. Para Maingueneau (2015a, p. 121) há papéis estatutários associados a certos comportamentos discursivos (professor, presidente, cantor, médico), a certos papéis propriamente verbais (interrogador, narrador, comentador, mediador) e a certas atitudes durante a enunciação (calma, benevolência). Cremos que ainda é preciso pensar, em função do próprio caráter de gênero nativo da Web, que há papéis associados a certos comportamentos digitais: curtir, comentar (com um texto ou com um emoji), compartilhar etc.

- Um lugar apropriado para o seu sucesso: pode se tratar de um lugar fisicamente descritível (escola, tribunal), mas o autor afirma que "para a Web, para emissões de rádio e de TV, para textos escritos, trata-se de espaços de outro tipo" (2015a, p. 121). Os exemplos dados pelo autor rompem com a lógica do espaço físico, uma vez que é possível determinar um espaço para a produção do enunciado, mas nunca o de recepção. A imprevisibilidade do controle sobre a circulação é característica inerente do digital: não é possível determinar com precisão o interlocutor, ainda que a cena englobante e a cena genérica selecionem mais ou menos previamente um determinado "público" a ser alcançado: as lives de palestras geralmente são vistas por professores e alunos; a de um político é vista por seus eleitores, a de um cantor por seus fãs. Ainda assim, o alcance de circulação não impede que pessoas entrem em palestras ao vivo para vandalizar, a oposição para questionar o ator político e curiosos que desconhecem o cantor para escutá-lo. Ponto importante: a palestra que sai do "presencial" para o virtual sai também da sala de conferências da universidade, o político sai do seu palanque, o cantor de seu palco; implica dizer que se o discurso não digital ou mesmo o "pré-digital" conferia ao espaço físico também um jogo regulatório de seus interlocutores, enquanto o digital adiciona um ponto importante de debate: sem espaço físico próprio, não há "portas" que se fechem ao desconhecido.

- Um modo de inscrição na temporalidade: referente à periodicidade ou à singularidade das enunciações, "sua duração previsível, sua continuidade, seu prazo de validade" (2015a, p. 122). Nessa esteira de pensamentos, podemos pensar em temporalidade 


\section{REVISTA DA ABRALIN}

digital: sua composição digital leva a live também a outras relações com sua inscrição no tempo, uma vez que ela é sempre síncrona, por um lado, mas uma vez gravada, permanece por tempo indeterminado na Web, o que faz com que as próprias condições de produção da live sejam alteradas conforme vista ao vivo ou gravada. Mudam-se os interlocutores, o contexto sócio-histórico (e ideológico). Também haverá sua temporalidade de periodicidade, conforme prevista por Maingueneau, a ser realizada com frequência semanal ou única, dependendo de sua finalidade.

- Um suporte: relacionado à existência material do enunciado, o suporte é associado ao transporte e, eventualmente, o arquivamento do texto. Assim, para muitos autores, as redes sociais podem ser consideradas um suporte, uma vez que servem de veículo para a materialização dos enunciados. No entanto, concordamos com Paveau (2017): a noção de suporte é dualista e, ao ter em conta apenas sujeito e linguagem, exclui a participação mais ou menos ativa da máquina.

- Uma composição: um gênero de discurso é caracterizado por partes e modos de encadeamento dos quais o falante tem mais ou menos certa clareza. A grande diversidade de planos de texto é o que vai caracterizar as lives, uma vez que há no vídeo ao vivo enunciados sendo produzidos pelo sujeito que preside a cena, mas também a própria rede que o hospeda terá caixa de comentários, sugestões de outros vídeos, hiperlinks, descrição do vídeo etc. Desse modo, a composição genérica das lives é heterogênea e engloba distintos rituais de fala.

- Um uso específico de recursos linguísticos e de dispositivos técnicos: há à disposição do locutor um repertório de variedades linguísticas que, para Maingueneau, sofrem restrições por parte do gênero do discurso. No entanto, tendo em vista o protagonismo da cenografia em detrimento da cena genérica na Web, podemos afirmar que são as cenografias, no caso das lives, que restringem e regulam as variedades linguísticas que the favorecem a encenação. Além disso, há uma gama de dispositivos (celulares - whatsApp, chats...) que constroem um efeito de interatividade com os destinatários e ampliam as lives para além das suas próprias delimitações.

Com base na compreensão, ainda que inicial, da heterogeneidade de constituição da cena genérica de uma live é que podemos observar que a cenografia engendrada parece tomar papel central na discussão, uma vez que em função dela vários dos tópicos anteriores sofrerão mutações. Com isso, a cenografia passa a ocupar o lugar de protagonista da encenação, determinando a constituição de outros elementos da cena mais do que sendo determinada. Pensando na disposição da cena de enunciação pressuposta por esse gênero nativo da Web, distintas cenografias podem ser mobilizadas: é possível fazer uma live a partir de uma cenografia professoral, em se tratando de alguém que se propõe a ensinar 


\section{REVISTA DA ABRALIN}

algo aos internautas; uma cenografia científica, quando pesquisadores, por exemplo, explicam a pandemia de 2020; uma cenografia íntima, quando o sujeito expõe fatos de sua intimidade em tom confessional aos seus seguidores. As possibilidades são inúmeras, uma vez que cada vez mais os sujeitos têm aderido ao uso de vídeos ao vivo para as mais distintas funcionalidades. Sob o termo "live", comportamos, com o advento da conectividade e consequente efemeridade, distintas condições de produção que levarão a distintas condições de circulação. Então, é sabido que a live de um cantor circule distintamente da live de linguistas que se propõem a discutir um tema, que também terá outros modos de circulação de uma live presidencial. Como afirma Paveau (2017), a especificidade especialmente das ferramentas ofertadas por cada rede social promoverá, também, essa distinção de circulação de enunciados, uma vez que a "clicabilidade" está ligada ao engajamento do público, o formato de compartilhamento (público ou entre amigos), se hashtags são utilizadas, divulgação etc.

Cabe, então, além de considerar as determinações técnicas de elementos não humanos, pensar que cada cenografia está ligada, de alguma maneira, ao seu agenciamento, aqui entendido como um conjunto de estratégias, de dimensão não verbal, ligadas à cena genérica: jogo de luz, uso ou não de microfone, ter ou não uma biblioteca ao fundo, escolha dos objetos que poderão ser vistos pelo outro etc. Para tratar da questão do agenciamento, conceito relativamente novo no conjunto da obra de Dominique Maingueneau, o autor cita como exemplo o uso do microfone em missas. Se antes, sem microfone, do alto do púlpito, o sujeito era levado a falar alto, com eloquência e deixava entrever apenas o seu busto "a parte nobre do corpo do orador, conferir autoridade a essa fala, que vinha do alto e era pronunciada com voz forte" (MAINGUENEAU, 2020, p. 147), a partir dos anos 1960 as igrejas passam a adotar o uso de microfone, o que tem efeito direto na construção do ethos dos pregadores: "Ao abandonarem o púlpito, eles passaram a falar no mesmo nível de seus ouvintes, diante deles, seu corpo pôde ser visto como um todo. Passou-se da cena retórica, que envolvia um orador, um "sobrelocutor", para cenografias de ethos mais íntimo, mais familiar." (p. 148). O agenciamento, que entendemos aqui como a composição não verbal da cena, restringe a cenografia: um sujeito atrás de uma escrivaninha favorece um ethos didático; um sujeito de jaleco branco favorece cenografias ligadas a um ethos científico, bem como um sujeito político que tira uma foto em sua casa, abre espaço para a criação de imagens de ordem íntima.

Com base nesse esboço teórico apresentado, podemos hipotetizar que, ao adotarmos um "cibergênero" como objeto de análise, que nasce na Web e não é meramente transposto para o digital, não podemos afirmar de maneira contundente que há enfraquecimento da cena genérica tal qual Maingueneau, mas entendemos que há uma pulverização de alguns aspectos do gênero: as cenografias verbais e digitais, que carregam consigo componentes específicos, como os iconotextuais, alargam as fronteiras genéricas rumo ao imprevisível. Em função disso, as lives surgem como um "guarda-chuva" genérico que abriga em si distintas finalidades, parceiros, temporalidade, composição, etc. Implica assim dizer que, ao tomar o discurso político como nosso objeto de estudo, observaremos movimentos distintos do que Maingueneau e Paveau vem propondo como uma teoria geral para se pensar novas situações de comunicação (MAINGUENEAU, 2015a) ou discursos digitais (PAVEAU, 2017). 


\section{REVISTA DA ABRALIN}

\section{Lives presidenciais}

Mais do que intimidade, descontração, emoções, as lives dão a circular regimes de verdade. Para que um discurso seja legitimado e aceito, o sujeito deve posicionar-se de acordo com determinados procedimentos que, em um dado momento histórico, instauram um verdadeiro e um falso. Há condições históricas de aceitabilidade dos enunciados que inscrevem a(s) verdade(s) a partir de jogos de poder e saber em uma sociedade. Para Nietzsche, de quem Foucault foi um renhido leitor, não existe verdade absoluta, uma vez que a verdade está condicionada a uma perspectiva. Nesse sentido, devido à necessidade humana de se acreditar em uma verdade é que o filósofo vai afirmar que há uma "vontade de engano" por parte da sociedade, já que buscar a verdade é esquecer que ela não existe em sua forma absoluta. Assim, a verdade seria uma necessidade cultural que possibilita a vida em sociedade, o que faz com que um grande número de pessoas crendo na mesma coisa faça com que esta coisa se torne verdadeira: “A apreciação de valor 'eu creio que isto e aquilo são assim' enquanto ESSÊNCIA da "verdade"' (FP 13: 9[38], Outono 1887 - Março 1888). Portanto, a verdade estaria condicionada a uma interpretação ou crença, a uma perspectiva: "Onde é necessário que algo seja tido por verdadeiro; não que este algo seja verdadeiro." (FP 13: 9[38], Outono 1887 - Março 1888)

Segundo Foucault (2011), a verdade se dá em uma relação entre o discurso e o saber, e é a partir do olhar sobre a história dessa(s) verdade(s) que se encontram o que o autor denomina "jogos de verdade", ou uma política da verdade, compreendida como um conjunto de processos, mecanismos e estratégias que permitem a cada pessoa pronunciar enunciados que serão considerados verdadeiros. Para o autor, toda sociedade possui procedimentos discursivos que tomam por finalidade conjurar poderes e perigos do discurso e inseri-los em uma vontade de verdade. Assim, para Foucault, a verdade é estrategicamente construída:

\footnotetext{
(...) se olharmos a trama, o grão da nossa sociedade, de nossa civilização, de nossas instituições, perceberemos que no fundo temos, sempre, técnicas, rituais, instituições que tem por função determinar, isolar momentos específicos ou lugares diferenciados, momentos e lugares a partir dos quais a verdade poderia, enfim, eclodir; como se, finalmente, a verdade não estivesse em toda parte, nem o tempo todo, mas como se devesse haver lugares em que a verdade explode e aparece, momentos em que verdade pode ser apreendida, momentos em que ela vem à tona. Há, portanto, toda uma geografia cultural da verdade (FOUCAULT, 2014, p. 65)
}

Considerando a noção de verdade a partir das afirmações de Nietzsche, para quem a vontade de verdade das pessoas é apenas uma ilusão de perspectiva, isto é, uma vontade de engano, é que pensamos nos efeitos de verdade construídos no discurso do Presidente da República, uma vez que não só o sujeito se apresenta como o detentor da verdade contra uma mídia supostamente mentirosa, como lança mão de uma série de dados, fatos e argumentos para corroborar esse regime de verdade, o que implica dizer que a perspectiva da verdade apresentada por ele é tomada pelo interlocutor, por sua vontade engano, como a verdade; a partir disso, os sujeitos, sempre interpelados por seus posicionamentos, serão instados por uma verdade ligada à questão de perspectiva no engendramento da estrutura e do acontecimento dos discursos. Interessa-nos, aqui, compreender como 


\section{REVISTA DA ABRALIN}

ocorre, por meio das lives, a produção de um discurso verdadeiro, suas técnicas, seus rituais, suas relações institucionais.

Jair Messias Bolsonaro, atual presidente do Brasil, teve inúmeros embates com a mídia, declaradamente, conforme suas afirmações, parcial e mentirosa. A partir da necessidade, então, não só de se dar a ver mas também de trazer a verdade para o eleitorado, o presidente passou a gravar vídeos ao vivo sobre os mais diversos temas, além de abrir lives "espontâneas" em diversos momentos do expediente. Assim, já em campanha eleitoral o então candidato passou a publicar distintos vídeos para informar o eleitorado. Depois de sua posse, o presidente viu a necessidade de formalizar tal empreendimento, agendando, desse modo, um horário com o público para a abertura de suas lives: toda quinta-feira às 18h30. Compreendendo a diversidade na constituição dessa cena genérica é que, a partir de nossas estratégias analíticas, tomaremos como material as lives produzidas pelo presidente às quintas. Acreditamos que a mobilização da cenografia presidencial, junto de um agenciamento específico, faz com que haja uma nova forma de se governar e de se pensar a própria governabilidade, criada a partir do efeito de proximidade e do discurso verdadeiro para o povo.

Desde 7 de março de 2019, data de sua primeira live presidencial ${ }^{1}$, Bolsonaro produziu inúmeras lives, todas às quintas, trazendo diferentes convidados e sempre acompanhado por uma intérprete de Libras. Geralmente, são gravadas com apenas uma câmera no Palácio da Alvorada e têm duração média de 30 minutos. Na primeira delas, ele pontua:

\footnotetext{
Nós pretendemos toda quinta-feira, às 18h30, fazer uma live sobre os assuntos mais importantes da semana, nós trataríamos bem como colheríamos né as maiores dúvidas que vocês deixam nos comentários pra que a gente possa semana que vem tratar desse assunto e assim sendo dar uma resposta à demanda de todos vocês e buscar soluções. Gostaríamos muito que vocês apresentassem propostas e ideias do que nós poderemos fazer para atender à população e também obviamente deixar a vida de vocês mais fácil...sabemos que muita coisa tá errada (...) num primeiro momento nem tanto fazer, desfazer muita coisa que foi feito de errado ao longo desses 20 anos.
}

Tomando o recorte anterior como uma espécie de epígrafe do que estaria por vir em suas lives, ali já vemos importantes pontos que aparecerão em muitas delas: "os assuntos mais importantes da semana" são trazidos por ele, frequentemente para que possa revelar a verdade para o público; o "inimigo comum" surge no enunciado "muita coisa foi feito de errado nos últimos 20 anos" e, além disso, o efeito de proximidade promovido pela utilização das redes é construído quando o sujeito diz para o seu eleitorado que deixe dúvidas nos comentários, mostrando que o seu governo estaria aberto às sugestões do povo para tornar "sua vida mais fácil", indo ao encontro do que Rosanvallon (2008) tem defendido como uma das formas de legitimidade da democracia: a necessidade do povo em se fazer ouvido faz com que se crie a necessidade de proximidade com instâncias do poder. Para além da reflexão linguística que envolve a questão, toda ela está entrelaçada aos recursos disponibilizados pela plataforma utilizada, que fazem com que o usuário possa estar conectado ao ator político. Observemos tais asserções, de forma mais detida, a partir dos recortes que se seguem.

1 Disponível em: <https://www.youtube.com/watch?v=cOWlW_3zcw4.>Acesso em: 30 jun. 2020 


\section{REVISTA DA ABRALIN}

Nas lives, Bolsonaro utiliza o espaço de fala para, especialmente, trazer a verdade:

i. A gente vê a imprensa, por outro lado, criticando, falando mal do PIB, falando "pibinho", "pibinho", falando não sei o que. Se a imprensa ainda produzisse alguma coisa, produzisse verdade, o Brasil estaria muito melhor com toda certeza, mas não produz verdade. Eu estou há quase duas semanas sem falar com a imprensa. O que acontece? Quando você fala, eles deturpam, quando você não fala, eles inventam. (Live de 5/3/2020 ${ }^{2}$ )

ii. A economia deslanchou, foi muita coisa destravada, o Brasil tá crescendo, aqui em Brasília bateu o que $150 \%$ o volume de negócio, o que 150\%? 150\% o volume de negócio no comércio local, o Brasil todo tá nessa fase, é a economia crescendo, é a confiança na equipe do governo, e outros dados aí: o dólar fechou quase $\mathrm{R} \$ 4,00$, está $\mathrm{R} \$ 4,06$, quase $\mathrm{R} \$ 4,00$, chegou a bater $\mathrm{R} \$ 4,28$ se não me engano, então a economia tá reagindo bem. A taxa SELIC o pessoal já sabe $4,5 \%$ isso quer dizer que a gente vai pagar o ano que vem menos 110 bilhões de reais, esse ano nós pagamos mais de 1 bilhão de real de juros por dia, realmente pegamos uma dívida fantástica aí e realmente a equipe do Paulo Guedes, não é o Paulo Guedes sozinho, é um ministério muito grande vem fortemente trabalhando nesse pedaço. Até perguntei pra ele se no ano que vem vai ser a mesma batida, falou que vai, continua com o espírito aí de garoto do colégio militar de Belo Horizonte. (Live de $26 / 12 / 2019^{3}$ )

iii. O [Sérgio] Moro tem um potencial enorme, ele é adorado no Brasil, o pessoal fala dele candidato a presidente, pô, se o Moro vier, que seja feliz, não tem problema, vai estar em boas mãos o Brasil, tá certo? E eu não sei se vou vir candidato em 2022, eu não sei, se estiver bem, pode ser que eu venha, se não estiver, tô fora. E outra coisa, já cansei de dizer que tem milhões de pessoas melhor do que eu pra disputar uma eleição. Vocês não podem fazer aquele joguinho de fogo amigo pra entregar pra esquerdalha, como a Argentina fez, de entregar pra esquerdalha em 2023, vocês vão ver o que é bom pra tosse, esses caras vão ficar 50 anos pra sair daqui. (Live de 26/12/2019)

A partir dos trechos transcritos de seus vídeos, observamos que a construção desse discurso verdadeiro por meio de um efeito de proximidade possibilitado pelas redes repousa em quatro aspectos: (i) em se dizer alvo de mentiras e reafirmar que é ele quem diz a verdade; (ii) trazer dados, números e estatísticas para amparar o regime de verdade; ainda em (ii), demonstrar intimidade com outras figuras políticas mais do que uma relação profissional; (iii) reafirmar o inimigo da nação: a esquerda.

\footnotetext{
2 Disponível em: <https://www.youtube.com/watch?v=K8z5SUbkZT8>. Acesso em 10 mar. 2020.

3 Disponível em: <https://youtu.be/YRkhkGbsYHw>. Acesso em 10 mar. 2020.
} 


\section{REVISTA DA ABRALIN}

Em (i), "Se a imprensa ainda produzisse alguma coisa, produzisse verdade, o Brasil estaria muito melhor com toda certeza, mas não produz verdade", o sujeito desqualifica o discurso midiático a partir de um regime de verdade. Segundo Gregolin, "[n]a sociedade contemporânea, a mídia é o principal dispositivo discursivo por meio do qual é construída uma 'história do presente' como um acontecimento que tensiona a memória e o esquecimento." (GREGOLIN, 2007, p. 16). Tal história do presente aparenta ser frequentemente questionada pelo sujeito que, por meio dos vídeos on-line, parece querer recriá-la a seu modo, em seu discurso e, assim, a partir do esquecimento de que ele não é a origem do sentido, recriar a própria cena de enunciação, engendrando cenografias - entendidas por Maingueneau como base de uma encenação singular da enunciação" (MAINGUENEAU, 2015b, p. 70, tradução nossa) - variadas: ele é o entrevistador e o entrevistado, o apresentador do jornal e o comentarista. Ainda em "O que acontece? Quando você fala, eles deturpam, quando você não fala, eles inventam." o sujeito opera a desqualificação do outro para legitimar a sua cena de enunciação, na qual ele é a única fonte do dizer e a verdade. Afirmamos, portanto, que a live não só produz efeito de proximidade, mas produz a construção de um discurso verdadeiro, porque seu interlocutor não só está próximo a esse corpo que se dá a ver ao vivo, quase íntimo, mas também está próximo a essa verdade que os torna quase cúmplices em uma batalha contra o mal: a mídia mentirosa, a esquerdalha etc. Sobre isso, Gregolin, citando a microfísica do poder proposta por Foucault, afirma que

\footnotetext{
Pulverizados em todo o campo social, os micropoderes promovem uma contínua luta pelo estabelecimento de verdades que, sendo históricas, são relativas, instáveis e estão em permanente reconfiguração. Eles sintetizam e põem em circulação as vontades de verdade de parcelas da sociedade, em um certo momento de sua história. (GREGOLIN, 2007, p. 17)
}

Assim, esse eleitorado, em sua vontade de verdade (ou de engano, como diria Nietzsche), adere aos discursos ali instaurados na cena que se compõe pela produção e circulação do vídeo nas redes sociais.

Sobre a construção do efeito de proximidade instaurado pela live, o sujeito ainda vai trazer não só uma variedade linguística menos formal que lhe é típica, recriando um tom de descontração, mas também, a partir disso, vai se mostrar "íntimo" de outras figuras políticas. Em "Até perguntei pra ele se no ano que vem vai ser a mesma batida, falou que vai, continua com o espírito aí de garoto do colégio militar de Belo Horizonte." o sujeito não só pontua que perguntou pessoalmente ao ministro, como ainda aparenta intimidade ao falar de sua infância. Isso faz com que o ethos de competência, sempre ligado ao sujeito político, seja tecido a partir dos signos da intimidade: ele não só governa o país, ele é íntimo de seus ministros. No entanto, atada a isso está a informatividade do enunciado: há diversos dados sobre economia sendo apresentados, o que também é da ordem do discurso verdadeiro, uma vez que tendo em vista que a mídia é mentirosa, então ali será o espaço para trazer a verdade sobre os reais dados da economia. Entrelaçando na cena a intimidade, a descontração e a informatividade, a cena de enunciação, em toda a sua inerente teatralidade, passa a (re)criar efeitos de sentido na ordem da verdade cúmplice, da verdade quase entre amigos.

Por fim, o inimigo em comum deve ser combatido. Em "vocês não podem fazer aquele joguinho de fogo amigo pra entregar pra esquerdalha, como a Argentina fez, de entregar pra esquerdalha em 2023, vocês vão ver o que é bom pra tosse, esses caras vão ficar 50 anos pra sair daqui." o mecanismo de 


\section{REVISTA DA ABRALIN}

construção do enunciado o leva para o tom de conselho/ameaça ao interlocutor. Dessa forma, as características desse tecnogênero, conforme nomenclatura de Paveau, permitem ao sujeito interagir, uma vez que ele pode não só se dirigir ao público, mas pode ler respostas e comentários em tempo real se assim desejar. O endereçamento de sua fala ao interlocutor, mais uma vez, assim defendemos, vai estreitar a proximidade entre eles, gerando uma cena cúmplice, dotada de uma vontade de verdade do seu eleitorado que vai sendo, pouco a pouco, construída e reconfigurada na abordagem de diversos temas.

Em relação ao agenciamento da cena, boa parte das lives são realizadas no mesmo ambiente, composto por vasta coleção de livros e uma mesa enorme, que deixa entrever grande quantidade de papéis, geralmente em desordem:

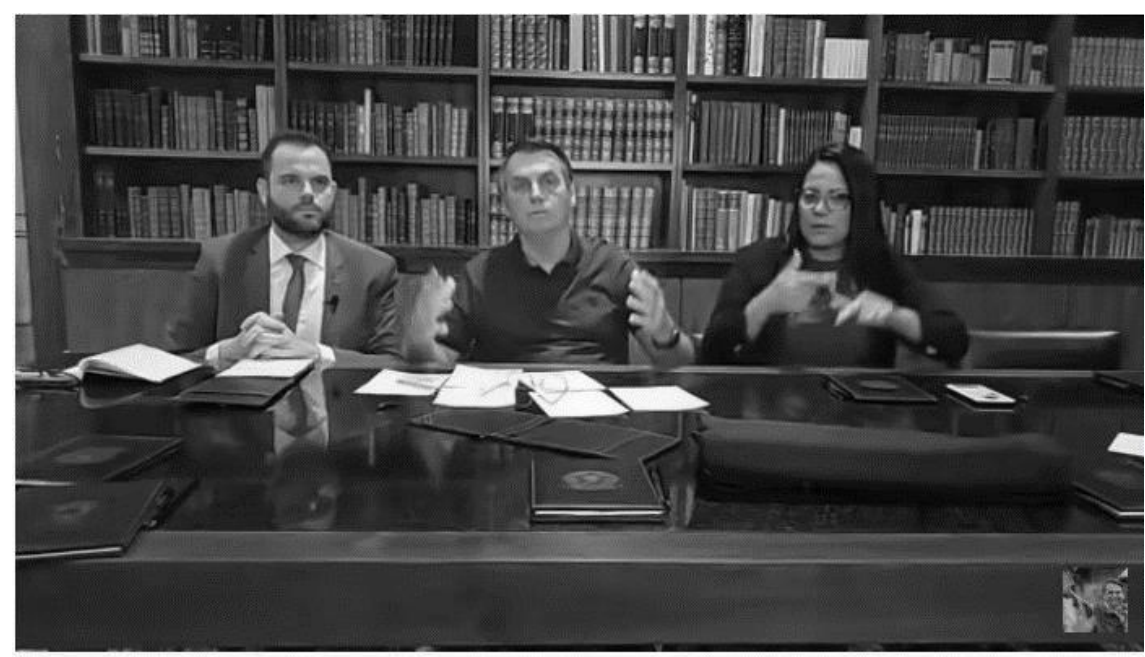

Live de quinta-feira com o Presidente da República (05/03/2020). Temas na descrição:

87.856 visualizações Il $20 \mathrm{MIL}$ qI $171 \Rightarrow$ COMPARTILHAR $\equiv+$ SALVAR $\ldots$

FIGURA 1 - Printscreen da live de 5 de março

Fonte: Youtube

O agenciamento da cena também constrói efeitos de sentido da ordem da verdade, amparada, semioticamente, pela intelectualidade socialmente atribuída aos livros. Assim, esse corpo político, que se dá a ver entre tantos livros, traz para a cena o que é da ordem do intelectual, do científico, do conhecimento, o que alicerça aquilo que está sendo dito, uma vez que dados e estatísticas são sempre apresentados nas lives como forma de se trazer a "verdade que a mídia não traz" para o público. Ainda é preciso observar que, apesar do outro estar de terno, o sujeito político que ocupa o maior cargo da nação está de camiseta. Mais uma vez, recria um mundo éthico da ordem do popular, do homem do povo. Assim, o não verbal agencia o que é fiado na ordem do verbal: por um lado, o discurso verdadeiro ligado ao universo imagético da intelectualidade de ter livros, por outro, o homem descontraído, que se dirige ao povo, que é próximo. Ademais, esse efeito de proximidade é 


\title{
REVISTA DA ABRALIN
}

corroborado pela presença de três pessoas que estão no mesmo nível, isto é, embora Bolsonaro figure ao centro da live, o seu assessor e a intérprete de Libras estão ao seu lado. Não há uma sobreposição, pelo menos em termos de efeito produzido, de uma pessoa sobre outra.

Cumpre destacar o papel da intérprete em Libras nas lives. A presença dessa intérprete para as pessoas surdas no mesmo nível em que está o locutor e o seu assessor contribui para conferir ao governo um ethos tanto de proximidade quanto compassivo, que tem a vontade de ajudar as pessoas da comunidade surda, buscando incluir todos indistintamente na comunidade nacional. A presença da intérprete no mesmo nível das outras pessoas que compõem a cena, diferentemente de outras em que os profissionais ficam restritos a um "cantinho" do vídeo, reforça o sentimento de um governo piedoso e inclusivo.

O efeito de proximidade também é corroborado pela aparente descontração em cena e certo caráter de "feito em casa" que pode ser associado à própria genericidade da live:

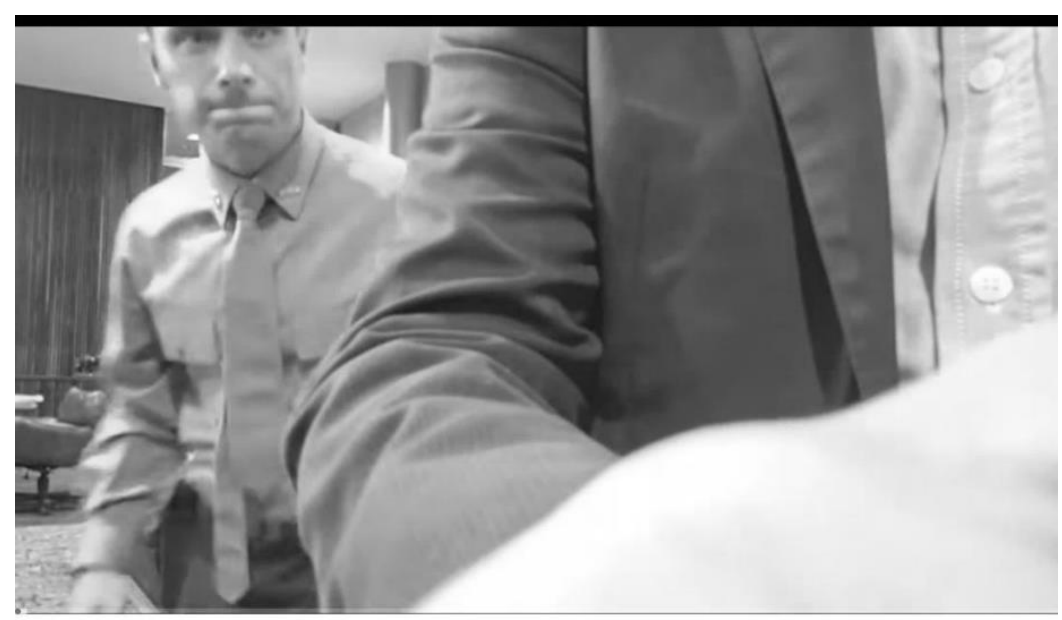

\section{Presidente Bolsonaro: Live da Semana - $30 / 07 / 2020$}

\author{
190.893 visualizações $\cdot 2$ semanas atrás
}

FIGURA 2 - Printscreen da live de 30 de julho Fonte: YouTube

Na live de 30 de julho, antes de iniciar, é possível ver dois homens ajeitando a câmera, enquanto Bolsonaro se dirige a eles descontraidamente. $\mathrm{O}$ efeito de proximidade é criado por aquilo que a live engendra: o vídeo ao vivo em casa, sem grandes produções, fazendo com que a relação entre público e privado se reorganize em função do próprio agenciamento da cena.

Por fim, consideramos importante destacar alguns enunciados relacionados à COVID-19:

iv. A gente lamenta aí o requerimento do senhor Humberto Costa, PT de Pernambuco, que quer fazer com que o pobre não tenha acesso a hidroxicloroquina. E se não tiver acesso, o que pode acontecer? Sumir das farmácias a hidroxicloroquina, vai pro câmbio negro 


\section{REVISTA DA ABRALIN}

aí, vai valer mil reais, dois, cinco mil reais uma caixa de hidroxicloroquina. Eu apelo ao senhor Alberto Costa, que já foi Ministro da Saúde, como não tem outro remédio, deixe o pobre, o idoso, aquele que tem algum tipo de doença, fazer o uso da hidroxicloroquina de graça nos hospitais, eu peço quase que pelo amor de Deus, isso é vida. (Live de $\left.21 / 5 / 2020^{4}\right)$

v. O PT não pode tirar o direito de lutar pela vida de qualquer um. Cada vez mais eu me convenço que é uma briga ideológica, uma briga partidária isso aí. Desde o começo eu falo da hidroxicloroquina, por quê? Eu sei que não sou médico, eu cumpro qualquer missão, mas não sou médico não, sou mergulhador também (...) mas a gente tem que dar uma esperança. A minha mãe tem 93 anos de idade, estava previsto uma viagem (...) e por que eu cancelei? Porque fiquei sabendo que ia ter certas aglomerações e a imprensa ia bater em mim e vai que eu visito a minha mãe e ela pega o coronavírus, vão falar que eu infectei a minha mãe. (Live de 21/5/2020)

vi. A OIT (Organização Internacional do Trabalho) disse que aqui na América Latina, incluída aí o Brasil obviamente, o poder aquisitivo dos informais caiu $80 \%$. Então vamos supor aí um trabalhador informal que leva 2 mil por mês vendendo aí churrasquinho de gato, biscoito Globo na praia, se ele ganhava 2 mil por mês, perdendo aí $80 \%$ tá passando pra $\mathrm{R} \$ 400$ em média (...). Por isso a gente acha que o Brasil não suporta mais por parte em alguns estados ter esse bloqueio aí tão grande no comércio (Live de 14/5/2010 ${ }^{5}$ )

Ainda consideramos importante para o que se defende aqui levantar enunciados das lives em período de pandemia. A COVID-19, doença causada pelo coronavírus SARS-CoV-2, atingiu de forma pandêmica a população mundial, somando, em outubro de 2020, 42 milhões de casos e mais de um milhão de mortos no mundo ${ }^{6}$, o que fez com que protocolos de saúde fossem adotados pelos países como um todo, sobretudo aqueles divulgados pela OMS (Organização Mundial da Saúde). Bolsonaro, declarando-se em diversos momentos na contramão de qualquer orientação da OMS, passou a divulgar em suas lives dados e informações sobre a pandemia, tratamentos etc. Um exemplo disso é o controverso uso de hidroxicloroquina, desaconselhado pela OMS por seus efeitos colaterais e por não apresentar eficácia comprovada. Apesar das recomendações da OMS estarem amparadas pelo

\footnotetext{
4 Disponível em: <https://www.youtube.com/watch?v=CaTtyaM5Jlw\&t=2017s>. Acesso em 25 mai. 2020.

5 Disponível em: <https://www.youtube.com/watch?v=S28DvOuB6cM>. Acesso em 25 mai. 2020.

6 Dados apresentados pelo Google diariamente. Disponível em: <https://news.google.com/covid19/map?hl=ptBR\&gl=BR\&ceid=BR:pt-419>. Acesso em 25 out. 2020.
} 


\section{REVISTA DA ABRALIN}

discurso científico, que, geralmente, é tido como um argumento de autoridade ou aceito como um discurso de verdade, já que ampara as crenças de boa parte da sociedade, o discurso do presidente adquire igualmente efeito de verdade. Primeiramente, porque alicerçado no fato de que "a mídia mente" e de que há um "inimigo a ser vencido", a construção da cena íntima, em que o sujeito possui a verdade e partilha com seu público cativo, vai sendo fiada.

Em (iv) o "inimigo da nação", o PT, representado pelo senador Humberto Costa, é trazido para se afirmar que o médico de Pernambuco "quer fazer com que o pobre não tenha acesso a hidroxicloroquina". Na construção dos efeitos de verdade criados sobre o uso de medicamento, que o sujeito defende apesar das contraindicações da OMS e cientistas do mundo todo, o sujeito mobiliza o outro para apontá-lo como inimigo do pobre: "deixe o pobre, o idoso, aquele que tem algum tipo de doença, fazer o uso da hidroxicloroquina de graça nos hospitais, eu peço quase que pelo amor de Deus, isso é vida". Apesar do próprio site do Senado trazer como informação que os senadores estavam questionando o uso da cloroquina por falta de estudos científicos ${ }^{7}$, o sujeito afirma que a motivação seria puramente "politicagem do inimigo", como se vê em (v) "O PT não pode tirar o direito de lutar pela vida de qualquer um. Cada vez mais eu me convenço que é uma briga ideológica, uma briga partidária isso aí", o que cria efeitos de sentido da ordem do "mal", afinal, o outro tira "o direito de lutar pela vida" dos mais pobres. Assim, na desqualificação do outro, seus valores morais são tecidos, e o sujeito passa a adquirir contornos humanos, empáticos, além de criar um discurso verdadeiro, o que se ressalta com "Eu sei que não sou médico, eu cumpro qualquer missão, mas não sou médico não, sou mergulhador também (...) mas a gente tem que dar uma esperança". Como dito anteriormente, o discurso científico ou especializado é valorizado e tido como argumento de autoridade socialmente, o que faz com que seja tomado como verdadeiro por boa parte da cultura mundial. Retomando então o seu não pertencimento a esse discurso de autoridade, reafirma seu caráter missionário, muitas vezes exaltado em suas campanhas ${ }^{8}$, para dizer que é preciso dar esperança às pessoas. A vontade de verdade do interlocutor passa a ser preenchida por essa preocupação com o povo, preocupação esta que só pode estar ligada à verdade. Ainda, entrelaçado à cena, o efeito de proximidade é corroborado quando pessoas de sua vida pessoal são mobilizadas. O sujeito traz a mãe de 93 anos idade para dizer que cancelou uma viagem e, portanto, tem compromisso com a pandemia, ao contrário do que todos dizem: à cenografia do bom filho se soma a do bom gestor.

Por fim, em (vi), mais dados são trazidos: "a OIT (Organização Internacional do Trabalho) disse que aqui na América Latina, incluída aí o Brasil obviamente, o poder aquisitivo dos informais caiu 80\%". Considerando que a doença só é visível por meio de números, já que se trata de um vírus, dados e estatísticas também são socialmente da ordem da verdade, uma vez que, teoricamente, não podem ser contestados. Então, apesar desse dado não poder ser localizado em lugar algum dos informes da OIT, a vontade de verdade (ou de engano) do interlocutor faz com que este adira a esse

7 Disponível em: <https://www12.senado.leg.br/noticias/materias/2020/05/21/senadores-questionam-liberacao-de-uso-dacloroquina-para-casos-leves-de-covid-19>. Acesso em 25 mai. 2020.

8 Jogando com a palavra "messias", que é também seu segundo nome. 


\section{REVISTA DA ABRALIN}

universo de sentidos criados, sobretudo por conta do duplo efeito de proximidade da verdade, em que ao mesmo tempo em que verdades são ditas, o relacionamento entre político-cidadão se estreita. E ainda, sabendo que a grande parcela da população que não aprova o isolamento social é contra o fechamento do comércio, o sujeito ainda traz "por isso a gente acha que o Brasil não suporta mais por parte em alguns estados ter esse bloqueio aí tão grande no comércio". Ao mesmo tempo em que se ausenta da responsabilidade, enquanto chefe de Estado, pela decisão de manter ou não o isolamento, tarefa repassada aos governos do Estado, ele reafirma que tem sido difícil de suportar, se colocando empaticamente ao lado do povo, embora contra todas as recomendações da OMS para que se mantenha a população em isolamento para evitar a transmissão comunitária do vírus.

É possível observar que os enunciados destacados apresentam um retorcimento de dados que convém em benefício de sua estratégia. No entanto, ao usar números, ainda que sem comprovação, o discurso adquire status de verdadeiro. Não existindo verdade absoluta, mas uma vontade de verdade que se condiciona ao apagamento de que tudo é questão de perspectiva, todo o engendramento da cena caminha para que isso seja corroborado. Assim, as redes criam o efeito de proximidade e o uso das lives para isso ampliou, também por conta do aparato técnico, essa relação político-cidadão; as lives, a partir da construção da cena, em que diversas cenografias são mobilizadas além de haver o agenciamento daquilo que o público pode ver, fortalecem o efeito de proximidade, além de passarem a fomentar a criação daquilo que é da ordem da verdade. A proximidade por meio da verdade criada pelas lives presidenciais é inédita: o uso da máquina para estreitar o vínculo com o eleitorado fez com que o discurso político digital circulasse de maneira nunca antes pensada, o que produz efeitos visíveis no modo de se governar.

\section{Para efeito de conclusão}

Na esteira da constante reconfiguração de práticas discursivas determinadas pelo discurso digital, estudar discurso político tem se mostrado um constante recriar de teorias e de métodos. A partir da compreensão de que o discurso político constantemente metamorfoseia-se, acreditamos que as lives presidenciais são uma nova forma de se fazer política, uma vez que criam um efeito de proximidade por meio de um discurso lido como verdadeiro: o eleitorado não só se sente próximo ao sujeito, mas adere a um regime de verdade, na ânsia de tornar-se cúmplice em uma cena de enunciação fabricada a partir da cenografia presidencial que engendra essa discursividade.

Com base no exposto, tentamos compreender, mesmo que minimamente, a estruturação das lives de modo a conceituá-las em vista das recentes propostas teóricas da Análise do discurso de orientação francesa. Considerando, assim, que a Web tem nos instado para que pensemos o discurso digital em função de sua circulação em detrimento das suas condições de formulação e que as especificidades fornecidas pelas redes sociais, tanto em termos de clicabilidade quanto em relação a sua efemeridade de circulação, somos impelidos, enquanto analistas do discurso, a repensar nossas 


\section{REVISTA DA ABRALIN}

teorias e práticas analíticas, sobretudo no que concerne à cena de enunciação, para dar conta da análise do discurso político digital. O "guarda-chuva" live parece comportar-se como uma cena genérica engendrada por todo tipo de cenografia diretamente relacionado à circulação dos enunciados, o que faz com que pensemos nas fronteiras genéricas que passam a ser pulverizadas em razão de suas cenografias.

Em vista dessas reflexões, as lives presidenciais brasileiras parecem ser o fruto mais recentemente colhido de toda a ressignificação de práticas que tem sido imposta ao discurso político pelas redes sociais, mais particularmente e pela web de uma maneira em geral. A relação político-cidadão, amparada pelo efeito de proximidade do discurso de verdade, é reestabelecida de forma a criar uma relação única entre ambos e contra todos, constituindo uma palco privilegiado para a governabilidade desse ator político.

\section{REFERÊNCIAS}

CARREON, R. O. Comunicação política e $(m)$ imagens de si: percursos a caminho do ethos semiotizado. 2018. $221 \mathrm{f}$. Tese (Doutorado em Linguística) - Universidade Federal de São Carlos, São Carlos, 2018.

CASTELLS, M. Redes de indignação e esperança Movimentos sociais na era da internet. Rio de Janeiro: Zahar, 2013. 271 p.

DIAS, C. Análise do discurso digital: sujeito, espaço, memória e arquivo. Campinas, SP: Pontes Editora, 2018.

FOUCAULT, M. Entrevista com Michel Foucault. In: M. FOUCAULT. Arte, epistemologia, filosofia e história da medicina: Ditos \& escritos VII. Rio de Janeiro: Forense Universitária, 2011, p. 157-168.

FOUCAULT, M. História da loucura e antipsiquiatria. Conferência pronunciada em maio de 1973. In: ARTIÈRES, Ph. et all. Michel Foucault. Rio de Janeiro: Forense Universitária, 2014.

GREGOLIN, M. R. Análise do discurso e mídia: a (re)produção de identidades. Comunicação, mídia e consumo: São Paulo, vol. 4, n. 11, p. 11-25, nov. 2007.

MAINGUENEAU, D. Discurso e Análise do discurso. São Paulo: Parábola editorial, 2015a.

MAINGUENEAU, D. La philosophie comme institution discursive. Limoges: Editora Lambert-Lucas, 2015b.

MAINGUENEAU, D. Variações sobre o ethos. São Paulo: Parábola, 2020.

NIETZSCHE, F.W. Fragments posthumes. Automne 1887 - mars 1888. Oeuvres philosophiques complètes, XIII. Paris: Galimard.

PAVEAU, M-A. Technodiscursivités natives sur Twitter. Une écologie du discours numérique. Epistémè: revue internationale de sciences humaines et sociales appliquées /, Center for applied cultural science, Korea university, Séoul, 2013, 9, p.139-176.

PAVEAU, M-A. L'Analyse du discours numérique. Dictionnaire des formes et des pratiques. Paris: Hermann. 2017.

ROSANVALLON, P. La Légitimité Démocratique - Impartialité, réflexixité, proximité. Paris: Seuil, 2008, 384p. 